\title{
Corynebacterium pseudotuberculosis, o agente etiológico da linfadenite caseosa em caprinos
}

\section{Corynebacterium pseudotuberculosis, the ethiological agent of the caseous lymphadenitis in goats}

\author{
LILLIA FERREIRA DE MOURA COSTA
}

* Professora de Microbiologia. Instituto de Ciências da Saúde. UFBA

\section{Resumo}

\begin{abstract}
Corynebacterium pseudotuberculosis é o agente etiológico da linfadenite caseosa em ovinos e caprinos, uma doença responsável por perdas econômicas graves no Nordeste do Brasil. Esta revisão se reporta à caracterização de Corynebacterium pseudotuberculosis através de aspectos morfotintoriais, morfologia colonial, reações bioquimicas e métodos moleculares.
\end{abstract}

\section{Palavras-chave}

Corynebacterium pseudotuberculosis, linfadenite caseosa, fosfolipase D

Prof $^{a}$ Lília Ferreira de Moura Costa

Laboratório de Bacteriologia

Departamento de Biointeração

Instituto de Ciências da Saúde

Universidade Federal da Bahia

Av. Reitor Miguel Calmon s/n Vale do Canela

40.110-100 - Salvador, Bahia, Brasil

e-mail: lilia@ufba.br 


\section{Introdução}

A linfadenite caseosa é considerada uma doença infectocontagiosa crônica que acomete caprinos e ovinos. É caracterizada por um quadro de abscesso dos linfonodos que apresentam material seco, purulento de cor branco-esverdeada (AYERS, 1977). Estes abscessos podem ser superficiais ou internos e pode haver, ainda, lesão de visceras. $\mathrm{O}$ agente etiológico da linfadenite caseosa é a bactéria Corynebacterium pseudotuberculosis (BENHAM; SEAMAN, WOODBINE, 1962; CAMERON; MINNAR, 1969; BATEY, 1986b).

C. pseudotuberculosis tem sido identificada em países em que existem grandes criações de ovinos e caprinos como Austrália, Argentina, Nova Zelândia, África do Sul e Estados Unidos (MERCHANT; PACKER, 1975; AYERS, 1977; ASHFAQ; CAMPBELL, 1979; BURREL, 1981) e em países da Comunidade Européia (STING; STENG; SPENGLER 1998). No Brasil, já foi isolada e caracterizada no interior da Bahia (MOURA COSTA et al., 1973) e em outros Estados do Nordeste (UNANIAN; SILVA; PANT, 1985). Benham, Seaman e Woodbine, em 1962, relacionam casos de linfadenite caseosa com isolamento de C. pseudotuberculosis em paises como Argentina, Chile, Uruguai, Canadá, França, Itália, GrãBretanha, União Soviética e Sudão. Trata-se, portanto, de um microrganismo cosmopolita.

No Nordeste do Brasil, existe uma alta prevalência de linfadenite caseosa nos rebanhos de caprinos (RIBEIRO et al., 1988; UNANIAN; SILVA; PANT, 1985). Os prejuizos nesta região do país provocados pela linfadenite são muito grandes, uma vez que muitos dos pequenos criadores têm a caprinocultura como uma das suas principiais atividades econômicas (RIBEIRO et al., 1988) e os abscessos levam a danos à pele e à condenação da carne, principalmente no comércio exterior (EGGLETON et al., 1991).

\section{Características do microrganismo e seu cultivo}

O agente etiológico da linfadenite caseosa, a bactéria C. pseudotuberculosis, foi descrito pela primeira vez por Nocard em 1885, posteriormente por Preisz (1891) Lehmann e Neumann (1896), Buchanan (1911) e Bergey (1923), citados por Benham, Seaman e Woodbine (1962). A nomenclatura atual foi adotada em 1948 na $6^{a}$ edição do Bergey's Manual, no entanto a designação Corynebacterium ovis é usada como sinônimo. C. pseudotuberculosis caracteriza-se como um bacilo Gram-positivo curto e irregular $(0,5$ a $0,6 \mu \mathrm{m}$ por 1 a $3 \mu \mathrm{m}$ ), podendo apresentar aspecto cocóide, e pode se mostrar isolado ou formando grupamentos irregulares ou em paliçada. São bacilos imóveis, anaeróbios facultativos, fermentativos e não formam esporos (BENHAM; SEAMAN; WOODBINE, 1962; BATEY, 1986b; MERCHANT; PACKER, 1975; QUINN et al., 1994).

Além das características morfotintoriais, C. pseudotuberculosis é caracterizado por provas bioquímicas, tais como: produção de catalase, produção de urease, redução de nitrato a nitrito e fermentação de carboidratos, sem produção de gás (MERCHANT; PACKER, 1975) como: maltose, manose, glicose, galactose (variável); não fermenta lactose (MUCKLE; GYLES, 1982; SONGER et al., 1988; SUTHERLAND; HART; BULLER, 1996; COSTA; SPIER; HIRSH, 1998); não tem atividade proteolitica, não hidrolisando a gelatina nem digerindo a caseína (MERCHANT; PACKER, 1975; QUINN et al., 1994). Songer et al. (1988) esclarecem que as diferenças en tre os resultados de algumas provas bioquímicas, principalmente de fermentação de carboidratos, podem ocorrer, em virtude dos diferentes métodos usados por diversos autores, e sugerem, ainda, que estas diferenças podem ser atribuídas à existência de biovariedades entre as cepas estudadas.

C. pseudotuberculosis é uma bactéria mesofilica, cuja temperatura ideal é $37^{\circ} \mathrm{C}$ (BENHAM, SEAMAN; WOODBINE, 1962; MERCHANT; PACKER, 1975), com um crescimento característico, graças às colônias hidrofóbicas formadas (BATEY, 1986b). Alguns autores relacionam um crescimento melhor em uma atmosfera de $5 \%$ de $\mathrm{CO}_{2}$ (BENHAM; SEAMAN; WOODBINE, 1962; MUCKLE; GYLES, 1982). 
C. pseudotuberculosis é exigente do ponto de vista nutricional, crescendo bem em meios enriquecidos como ágar sangue, ágar BHI ou caldo BHI ou enriquecidos com soro animal. Seu rendimento aumenta quando ao BHI é acrescentado extrato de levedura, triptona ou lactoalbumina (CAMERON; SWART, 1965). $\mathrm{O}$ crescimento da bactéria em meio líquido ocorre como uma película na superfície, sem turvação do meio. Esta película é desfeita pela agitação, formando-se, então, flocos que precipitam (CARNE, 1939; MERCHANT; PACKER, 1975; MUCKLE; GYLES, 1982). A película é atribuída aos lipídios de superfície, e a formação de uma película mais densa, a uma maior virulência (JOLLY, 1966). O fato de C. pseudotuberculosis crescer em meio liquido formando flocos dificulta a contagem de células viáveis e a padronização do inóculo. A formação de flocos, característicos, pode ser diminuida, e o rendimento da cultura aumentado pelo acréscimo de mono-oleato de sorbitan, Tween 80 (JOLLY, 1966; BATEY, 1986a). O acréscimo de Tween 80 ao meio leva ainda a um aumento da atividade hemolítica das cepas, quando comparadas com cepas cultivadas na ausência deste agente (SUTHERLAND; SPEIJERS, ANDRES, 1989).

No ágar sangue, são formadas colônias pequenas, de coloração branco-acinzentada, opacas e friáveis. Após vários dias de incubação, as colônias podem alcançar $3 \mathrm{~mm}$ de diâmetro e são de coloração creme (QUINN et al., 1994). Produzem $\beta$ hemólise, característica que pode não aparecer até 48 a $72 \mathrm{~h}$ de incubação (CARNE, 1939; CAMERON; SWART, 1965; QUINN et al., 1994). O pH ideal para o crescimento está entre 7,0 e 7,2 (MERCHANT; PACKER, 1975), mas, segundo Batey (1986a), C. pseudotuberculosis pode crescer bem em uma variação de $\mathrm{pH}$ de 7,0 a 8,0.

Biberstein (citado por Batey, 1986b) admite a existência de dois biotipos baseados na produção de nitrato redutase. A redução do nitrato a nitrito caracteriza cepas que infectam preferencialmente eqüinos, enquanto as cepas que infectam preferencialmente caprinos e ovinos são nitrato negativas (BATEY, 1986b;
COSTA; SPIER; HIRSH, 1998). Segundo trabalho de SONGER et al. (1988), os bovinos são infectados tanto por cepas nitrato positivas quanto por cepas nitrato negativas. Os autores sugerem que o biotipo que infecta eqüinos, e que apresenta sensibilidade à estreptomicina, seja denominado equi, enquanto o que infecta ovinos e caprinos, resistente à estreptomicina, seja denominado ovis. A análise através de enzimas de restrição confirma diferenças entre estes dois biotipos (SONGER et al., 1988; COSTA; SPIER; HIRSH, 1998; SUTHERLAND; HART; BULLER, 1996). As bases fenotipicas e genotipicas desta diferença de hospedeiro preferencial ainda não estão definidas.

C. pseudotuberculosis apresenta lipídios associados à parede celular à semelhança do ácido micólico de Mycobacterium tuberculosis, apesar de não apresentar álcool-ácido resistência. À presença destes lipídios é atribuído o crescimento padrão em meio líquido, formando flocos característicos (JOLLY, 1966). Estudos de microscopia eletrônica mostraram a presença de uma camada eletrodensa externa à parede celular, atribuida a estes lipídios. A remoção não diminui a viabilidade da bactéria. A atenuação gerada por repiques sucessivos está relacionada a um estreitamento desta camada lipídica (HARD, 1975). De acordo com Jolly (1966), esta camada lipídica dificultaria a fagocitose da bactéria, aumentando sua virulência. Para outros autores (BATEY, 1986b; SONGER et al., 1990), estes lipídios estão relacionados à citoxicidade. Zaki (1976) demonstrou que bactérias sujeitas a agentes químicos e físicos perdem a capacidade de matar camundongos, mas mantêm a propriedade de causar lesões piogênicas estéreis. $\bigcirc$ fator piogênico estaria relacionado a esta substância termo estável da parede celular. Cameron, Minnar e Purdon (1969) demonstraram que a extração por solventes deste componente lipídico não afetava a imunogenicidade da parede celular.

O lipídio de parede de C. psendotuberculosis foi caracterizado por cromatografia e espectrofotometria de massa que demonstrou que o ácido corinomicólico (IONEDA, 1993) guarda semelhança com os lipídios de superfície de 
Rhodococcus, Nocardia e Mycobacterium. Quando aquecidos a $300^{\circ} \mathrm{C}$, liberam duas subunidades. A subunidade $\alpha$ é um ácido graxo e a subunidade $\beta$ é um meroaldeído. A cadeia principal é formada por 32 carbonos, e existem anéis aromáticos (grupos benzoil) ligados a esta cadeia.

A produção de fosfolipase D foi encontrada por Songer et al. (1988) em todas as cepas estudadas. Este autor atribui à enzima uma importância na viabilidade de C. pseudotuberculosis. Mesmo as cepas mantidas em meios de cultura por mais de quarenta anos, segundo o autor, continuavam produzindo fosfolipase D. A fosfolipase D é caracterizada como uma exotoxina. Muitas de suas propriedades biológicas ainda não estão esclarecidas. São conhecidas algumas características, tais como: ação de hidrolisar lisofosfatidilcolina e esfingomielina; tem pI de 9,8; necessita de íons $\mathrm{Ca}$ e $\mathrm{Mg}$ para sua atividade; é tóxica para roedores de laboratório; e é capaz de lisar eritrócitos de carneiro em sinergismo com a colesterol oxidase e a fosfolipase C produzidas por Rhodococcus equi. A fosfolipase D é capaz de proteger eritrócitos de carneiro da lise por hemolisina estafilocócica (esfingomielinase). $O$ peso molecular de fosfolipase $D$ é de, aproximadamente, $31,5 \mathrm{kDa}$. Aparentemente, C. pseudotuberculosis não produz outra proteína hemolítica ou que tenha ação sinérgica. Outras bactérias produzem fosfolipases que estão envolvidas na patogênese de doenças. É necessário um maior conhecimento sobre síntese, regulação, secreção e mecanismo de ação da fosfolipase D para entender o seu exato papel na doença e no desenvolvimento de resistência ao patógeno (SONGER et al., 1990).

Em revisão de 1997, Songer relata que as atividades de fosfolipase D de C. pseudotuberculosis podem ser originadas de sítios diferentes da molécula. Segundo este autor, a atividade de hemólise sinérgica com a colesterol oxidase de Rhodoccocus equi, assim como a atividade esfingomielinase são abolidas com a inativação pela formalina, enquanto a ação de inibição da $\beta$ hemólise por toxina estafilocócica permanece. Uma bactéria modificada por uma mutação no gene que codifica a fosfolipase $\mathrm{D}$, quando inoculada em caprinos, mostrou uma capaci- dade reduzida de estabelecer uma infecção local e incapaz de causar granulomas em linfonodos regionais, confirmando que a fosfolipase D facilita a persistência e disseminação de C. pseudotuberculosis no hospedeiro (McNAMARA; BRADLEY; SONGER, 1994).

O gene da fosfolipase D de C. pseudotuberculosis já foi clonado e expresso em Escherichia coli, codificando uma proteina de aproximadamente 31,5kDa (SONGER, et al., 1990; HODGSON; BIRD; NISBET, 1990). Muitos estudos usando a exotoxina bruta ou parcialmente purificada mostram que a atividade da fosfolipase D sobre a esfingomielina na membrana das células do endotélio vascular parece ser importante na disseminação da bactéria do local da infecção para os linfonodos e que os anticorpos anti-fosfolipase D parecem limitar a disseminação no hospedeiro infectado (ALVES; OLANDER, 1999).

As proteinas resultantes da seqüência de genes de C. pseudotuberculosis biotipos ovis e equi, Corynebacterium ulcerans, assim como de Arcanobacterium haemolyticum demostram ser homólogas num percentual que varia de $64 \%$ a $97 \%$, e os anticorpos contra estas toxinas mostram grande reatividade cruzada (McNAMARA; CUEVAS; SONGER, 1995).

\section{Os antígenos de C. psendotuberculosis}

Além da fosfolipase D, outros antígenos foram mencionados por alguns autores. Parte destes antígenos aparecem no sobrenadante, como a fosfolipase D, enquanto outros estão associados à célula bacteriana.

Quanto aos antígenos ligados à bactéria, Ellis et al. (1991a) definiram por Western blotting onze antígenos de $20 \mathrm{kDa} ; 22,4 \mathrm{kDa} ; 31,6 \mathrm{kDa}$; $35,5 \mathrm{kDa} ; 36,3 \mathrm{kDa} ; 39,8 \mathrm{kDa} ; \quad 45,7 \mathrm{kDa}$; $56,2 \mathrm{kDa} ; 63,1 \mathrm{kDa} ; 79,4 \mathrm{kDa}$ e $100 \mathrm{kDa}$. Em trabalho posterior (1991b), o mesmo grupo identificou proteinas de $12 \mathrm{kDa} ; 25,1 \mathrm{kDa} ; 31,6 \mathrm{kDa}$; $36,3 \mathrm{kDa} ; 39,8 \mathrm{kDa} ; 63 \mathrm{kDa} ; 70 \mathrm{kDa} ; 75 \mathrm{kDa}$; $79,4 \mathrm{kDa} ; 100 \mathrm{kDa}$ e $120 \mathrm{kDa}$. Braithwaite et al. (1993), usando a coloração pela prata e Western blotting, isolaram proteínas com os seguintes 
pesos: $14 \mathrm{kDa} ; 30 \mathrm{kDa} ; 33 \mathrm{kDa} ; 36 \mathrm{kDa} ; 48 \mathrm{kDa}$; $58 \mathrm{kDa} ; 64 \mathrm{kDa} ; 84 \mathrm{kDa} ; 120 \mathrm{kDa}$. Muckle et al. (1992) caracterizaram, no extrato de células bacterianas, proteínas de $31,5 \mathrm{kDa} ; 40 \mathrm{kDa} ; 43 \mathrm{kDa}$; $64 \mathrm{kDa} ; 68 \mathrm{kDa}$ e $120 \mathrm{kDa}$. Sting, Steng e Spengler (1998), em trabalho com caprinos, revelaram, associados à célula bacteriana, antígenos de 20 a $120 \mathrm{kDa}$, dando ênfase aos antígenos de $30 \mathrm{kDa}$ e $55 \mathrm{kDa}$, como predominantes.

Dentre os antigenos secretados, Ellis et al. (1991b) relacionam antígenos de $20 \mathrm{kDa}$; 25,1kDa; 31,6kDa; 39,8kDa; 63kDa e 68kDa. Braithwaite et al. (1993) relatam o achado de antigenos de $31,5 \mathrm{kDa} ; 36 \mathrm{kDa} ; 56 \mathrm{kDa}$ e $63 \mathrm{kDa}$.

Walker et al. (1994) isolaram uma proteína secretada de $40 \mathrm{kDa}$, que, usada como vacina associada a hidróxido de alumínio, estabeleceu uma resposta protetora em $82 \%$ dos ovinos vacinados. Em outro trabalho, Wilson, Brandon e Walker (1995) clonaram e seqüenciaram o gene desta proteína de $40 \mathrm{kDa}$, demonstrando não haver homologia desta proteína com outras já seqüenciadas. A análise bioquímica da proteína revelou propriedade proteolitica, provavelmente pertencente ao grupo das serino-proteases.

\section{Patogenia de C. pseudotuberculosis}

A linfadenite caseosa é uma doença que compromete principalmente a pele do animal, uma vez que os abscessos podem drenar naturalmente, gerando soluções de continuidade na pele (AYERS, 1977). Quando ocorrem lesões internas, acarretam perda de peso, deficiência reprodutiva, podendo levar à morte do animal (ASHFAQ; CAMPBELL, 1979; BURREL, 1981). Pode ocorrer, ainda, diminuição da produção de lã, em ovinos, ou a condenação da carne (NAIRN; ROBERTSON, 1974).

A forma de contágio ainda é controversa, mas, provavelmente, ocorre através do contato entre o drenado do abscesso e a pele ou mucosas integras dos animais sadios, ou onde existam soluções de continuidade (BURREL, 1981; BATEY, 1986b), ou, ainda, através de aspiração de aerossóis (CHAPLIN et al., 1999). Segundo Paton et al. (1995), a fonte de microrganismos, em rebanhos ovinos, poderiam ser le- sões pulmonares clinicamente não diagnosticadas, responsáveis pela liberação das bactérias por aerossóis.

A partir da lesão inicial ou da porta de entrada, a bactéria chega até os linfonodos regionais, principalmente pré-crurais e pré-escapulares (em caprinos), onde produz a lesão caseosa característica (JOLLY, 1966; BATEY, 1986b). A disseminação da bactéria no organismo hospedeiro depende, principalmente, da exotoxina liberada com propriedade hemolitica e vasodilatadora (BENHAM; SEAMAN; WOODBINE, 1962; JOLLY, 1966; BURREL, 1981) com atividade fosfolipásica (BATEY, 1986b; SONGER, 1997).

Apesar de ser uma doença característica de caprinos e ovinos, C. pseudotuberculosis está relacionado com doença em eqüinos, nos quais a patologia mais freqüente é a linfangite ulcerativa, ocorrendo também abscessos peitorais, inguinais e abdominais (BATEY, 1986b). Em revisão feita em 1962, Benham, Seaman e Woodbine relatam casos de linfadenite caseosa relacionada com outras espécies como bovinos, veados e camelos, nos quais o agente isolado foi C. pseudotuberculosis. Segundo Songer et al. (1990), existe uma certa prevalência de abscessos superficiais causados por C. pseudotuberculosis em gado leiteiro no Oeste dos Estados Unidos. Existem, ainda, trabalhos que citam infecção em humanos, com um quadro clínico semelhante ao encontrado em caprinos e ovinos, relacionados com contato com estes animais (LOPEZ; WONG; QUESADA, 1966; BATTEY; TONGE, 1968; PEEL et al., 1997).

A doença apresenta um periodo de incubação longo, o que torna difícil a separação entre animais infectados e animais não infectados (BATEY, 1986b). A introdução de um animal infectado em um rebanho leva ao aparecimento de abscessos nos animais no período de dois a três anos. Uma vez introduzida a infecção em um rebanho, torna-se muito difícil a sua erradicação (AYERS; 1977; ALVES; OLANDER, 1999).

Existem dúvidas quanto à porta de entrada do C. pseudotuberculosis no organismo do animal e de como o microrganismo chega até os 
linfonodos. A hipótese mais aceita é a de que a infecção ocorra na pele ou mucosa e, a partir dai, chegue aos linfonodos ou a outros órgãos (BURREL, 1981; BATEY, 1986b). Os caprinos podem se infectar através da ingestão de microrganismos contaminantes do alimento, que podem ser ingeridos ou penetrar através de lesões na mucosa oral provocadas pela alimentação fibrosa (BURREL, 1981). A porta de entrada provavelmente difere entre caprinos e ovinos, já que estes sofrem soluções de continuidade na pele por ocasião da tosquia; outros comportamentos diferentes entre as duas espécies resultam em uma distribuição diferente dos abscessos (NAIRN; ROBERTSON, 1974; PATON et al., 1995; ASHFAQ; CAMPBELL, 1979). $O$ material fecal no campo também pode funcionar como fonte de infecção, uma vez que a bactéria pode permanecer viável por meses no ambiente (BURREL, 1981; BATEY, 1986b). A aspiração de aerossóis também é sugerida por Paton et al. (1995) como uma porta de entrada. O local mais evidente de funcionar como porta de entrada parece ser mesmo a pele, o que é sugerido pela distribuição dos abscessos nas carcaças dos animais (BATEY, 1986b).

Batey (1986b) relata estudos experimentais usando camundongos, que sugerem que a disseminação da bactéria do local da inoculação, livre ou dentro de fagócitos, ocorre rapidamente e é seguida de disseminação para órgãos como fígado, baço e rim. Nairn e Robertson (1974) observaram que as lesões viscerais em ovinos são concomitantes às lesões em linfonodos. A enzima fosfolipase D parece ter grande importância na disseminação da bactéria, uma vez que as membranas das células de mamíferos têm uma quantidade grande de fosfolipídios. Em ovinos, foi demonstrada a presença de uma grande quantidade de prostaglandina, induzindo uma resposta inflamatória local, que leva a um aumento da permeabilidade e a um deslocamento de fagócitos, que migram, então, para os linfonodos. O uso de antitoxina diminui a permeabilidade vascular e reduz a transferência da bactéria para os linfonodos regionais, protegendo do desenvolvimento da lesão (BURREL, 1981).
A infecção, seja em linfonodos, seja em outros órgãos, evolui com fagocitose, multiplicação intracelular de C. pseudotuberculosis e morte das células hospedeiras. Na infecção experimental, a lesão evolui com a segregação de microrganismos e células degeneradas por camadas de macrófagos e tecido fibroso (BATEY, 1986b). O tamanho da lesão parece ser determinado pelo número de microrganismos e pela presença de uma maior quantidade de lipídio citotóxico. Variações na evolução da doença ocorrem tanto em infecções experimentais quanto em naturais e, em um rebanho infectado, um animal pode ter anticorpos antitoxina sem apresentar lesões (NAIRN; ROBERTSON, 1974).

Jolly (1966) observou a evolução das lesões e notou que, quando havia uma predominância de macrófagos, elas se resolviam, e quando predominavam polimorfonucleares, as lesões cronificavam. Isto sugere que a resposta do hospedeiro é mais importante para a evolução da doença do que a virulência da bactéria. Existe uma tendência para que a bactéria seja eliminada. Em camundongos, as bactérias são eliminadas em 14 dias ou surge a lesão caseosa (BATEY, 1986b). Esta lesão é uma forma de conter a bactéria e evitar que ela se dissemine no organismo hospedeiro.

\section{Diferenciação de cepas de C. pseudotuberculosis através de técnicas de biologia molecular}

Microrganismos pertencentes a uma mesma espécie, mas a cepas diferentes, podem ser diferenciados através de técnicas de biologia molecular que permitem a observação de padrões baseados em pequenas diferenças na seqüência de DNA.

Das técnicas atualmente em uso, a PFGE ou eletroforese em gel de campo pulsado é das mais precisas e reprodutiveis. Nesta técnica, a cultura bacteriana pura é combinada a agarose fundida e colocada em pequenos moldes. O resultado são pequenos pedaços de agarose contendo o microrganismo inteiro. A bactéria é, então, sujeita a lise por detergente e enzimas e, depois, submetida à ação de uma enzima de restrição. Os 
fragmentos de agarose contendo a bactéria digerida são inseridos em gel de agarose e sujeitos a eletroforese em um aparelho em que a polaridade é mudada em intervalos determinados. Pode-se separar, por esta técnica, fragmentos de DNA de 10 a $800 \mathrm{~kb}$. O gel é corado por brometo de etídio, e o resultado fotografado e analisado em aparelhos digitais disponíveis comercialmente. Por esta técnica, a comparação de microrganismos relacionados é possivel, baseada na diferença de bandas geradas (TENOVER et al., 1995). Quanto maior o número de bandas diferentes, menos relacionadas são as bactérias. Esta técnica é considerada por muitos autores como o padrão-ouro dentre as técnicas de tipagem molecular (OLIVE; BEAN, 1999).

A técnica de fingerprint mais simples é a chamada REA (restriction endonuclease analysis) ou análise por endonucleases de restrição. Esta técnica consiste em, a partir do DNA cromossômico, fazer clivagens usando enzimas de restrição e, em seguida, uma eletroforese em gel de agarose e, corando com brometo de etídio, fotografar em UV. A análise por endonucleases de restrição pode ser usada não só para caracterizar a espécie, mas também permite a diferenciação em cepas. Esta diferenciação é possivel graças a pequenas alterações na seqüência de nucleotideos do cromossomo que origine sítios de clivagem diferentes. A desvantagem da técnica é que ela pode gerar muitas bandas a serem analisadas e, dessa forma, dificultar a diferenciação.

Uma outra técnica empregada para diferenciação entre individuos de uma mesma espécie, mas de cepas diferentes, é o chamado polimorfismo de comprimentos de fragmentos de restrição (RFLP). Esta técnica implica em uma digestão com endonucleases de restrição, seguida de eletroforese em gel de agarose e uma posterior transferência tipo southern para uma membrana onde é feita uma hibridização com uma sonda marcada. Esta sonda pode ser a seqüência do gene de frações $16 \mathrm{~S}$ ou $23 \mathrm{~S}$ do RNA ribossômico ou outra seqüência genética conhecida. A técnica de RFLP tem uma vantagem sobre a REA por demonstrar menos bandas a serem analisadas e comparadas (OLIVE; BEAN, 1999).
A técnica de RFLP pode ser feita, ainda, pela modalidade de PCR (reação de polimerização em cadeia) baseado em RFLP locus especifico. Nesta técnica, o locus a ser analisado é amplificado com primers específicos para o gene e, posteriormente, sujeito a análise dos fragmentos de restrição. Os fragmentos de DNA são separados em gel de poliacrilamida ou agarose e as bandas coradas com brometo de etídio. $\mathrm{O}$ locus escolhido pode ser o gene $16 \mathrm{~S}$ ou 23S; neste caso, tem-se uma variação da ribotipagem.

O chamado ensaio de DNA polimórfico randomicamente amplificado (RAPD) também é conhecido como PCR arbitrariamente primado. Esta técnica se baseia no uso de pequenos primers de 9 a 10 bases, que hibridizam com suficiente afinidade as seqüências de DNA cromossômico a baixas temperaturas de pareamento, de tal forma que podem ser usados para iniciar amplificação de regiões do genoma bacteriano. O número e a localização dos sítios de hibridização aos primers variam dentro de cepas de uma mesma espécie. É feita, em seguida, uma separação através de eletroforese em gel de agarose dos produtos da amplificação, e os padrões de banda devem, teoricamente, ser diferentes entre as cepas relacionadas.

A técnica REP-PCR (reação de polimerização em cadeia de seqüências repetitivas) é baseada em seqüências conhecidas como elementos palindrômicos extragênicos repetitivos. Estas são seqüências de 38bp que consistem de seis posições degeneradas e uma alça variável de 5bp entre duas porções palindrômicas conservadas. As seqüências REP já foram descritas em várias bactérias entéricas. Outra seqüência conservada é chamada ERIC ou seqüências de consenso repetitivas intergênicas enterobacterianas. As seqüências ERIC são elementos de $126 \mathrm{bp}$ localizados na região extragênica e altamente conservados. Muitos estudos mostram que a técnica REP-PCR tem grande correlação de resultados com a PFGE, porém com um poder discriminatório menor (OLIVE; BEAN, 1999).

Polimorfismo de comprimento de fragmentos amplificados (AFLP) é uma técnica baseada na amplificação de grupos de fragmentos 
de restrição de DNA gerados, por digestão, por enzimas de restrição. O DNA genômico da bactéria é extraído, purificado e sujeito a digestão por duas enzimas de restrição. Os fragmentos de restrição são ligados a conexões contendo um sítio de restrição e uma seqüência homóloga a um primer de PCR. Os primers usados contêm seqüências de DNA homólogas às conexões e uma ou duas bases seletivas na extremidade 3'. Dessa forma, os nucleotideos seletivos permitem a amplificação de apenas um grupo de fragmentos de restrição genômicos. Estes primers são marcados radioativamente por fluorescência, ou é usada a coloração por brometo de etídio. Segundo alguns autores, a técnica de AFLP é muito reprodutivel e tem a capacidade de diferenciar cepas relacionadas (SAVELKOUL et al., 1999).

O seqüenciamento do DNA em seqüenciador automático parece ser a melhor forma de diferenciar cepas ou subtipos, uma vez que as diferenças mostradas nas técnicas anteriores se baseiam em diferenças na seqüência de DNA. $O$ seqüenciamento começa com uma amplificação por PCR direcionada a uma região genética de interesse. Depois, é feito o seqüenciamento da região amplificada. A análise é feita automaticamente em equipamento apropriado, usando-se dideoxinucleotideos marcados com quatro diferentes corantes fluorescentes, cada um marcando um nucleotídeo diferente.

O seqüenciamento do DNA só pode ser dirigido a pequenas porções do DNA. É impraticável seqüenciar múltiplas ou grandes regiões do cromossomo. Por outro lado, as técnicas de biologia molecular, também chamadas fingerprint, como RFLP, PFGE, AFLP, permitem a análise do cromossomo inteiro, ao invés de pequenas porções do DNA, que podem conter ou não alguma variação (OLIVE; BEAN, 1999).

As técnicas de análise com enzima de restrição (REA) e de polimorfismo de comprimento de fragmentos de restrição (RFLP) foram usadas por alguns autores, visando a caracterização de C. pseudotuberculosis. A análise por enzimas de restrição (REA) foi feita por Songer et al. (1988), evidenciando diferenças no padrão de restrição, diferenciando as cepas nitrato redutase positivas das cepas nitrato redutase negativas, usando Eco RV e Pst I. O mesmo autor, clonando e seqüenciando o gene de fosfolipase $\mathrm{D}$, em 1990, constatou a presença de um sitio de restrição no biotipo equi para BamHI, flanqueando o gene da fosfolipase $\mathrm{D}$, ausente no biotipo ovis.

Um estudo comparativo de 13 cepas de C. pseudotuberculosis isoladas de origens diversas, através de RFLP usando ribotipagem (onde a sonda usada é derivada de gene da subunidade 16S do RNA ribossomal) mostrou diferença de bandas entre cepas nitrato negativas e nitrato positivas, usando Apa I, Pst I e Sst I, sendo que Pst I diferenciou uma cepa nitrato positiva das demais (SUTHERLAND; HART; BULLER, 1996). Em outro trabalho, Costa, Spier e Hirsh (1998), comparando 37 cepas de C. pseudotuberculosis de diferentes locais do mundo, usando também a técnica de RFLP com ribotipagem, as enzimas Apa I, Hind III, Pst I e Sst I, mostraram diferenças entre as cepas isoladas de grandes ruminantes e cepas isoladas de pequenos ruminantes, sendo que Pst I mostrou diferença em uma das cepas de pequenos ruminantes.

A técnica de RFLP associada a ribotipagem foi usada para identificar bactérias dentro de gênero Corynebacterium e Turicella, por Björkroth, Korkeala e Funke (1999), usando as enzimas de restrição Bst EII, Sma I, e Sph I, mostrando que a técnica pode ser empregada para caracterização de espécies do gênero Corynebacterium.

Literák et al. (1998) estudando, através de REA, RFLP e ribotipagem, as cepas de C. pseudotuberculosis isoladas de três surtos em ovinos e dois surtos em caprinos, na Eslováquia, concluíram pertencer ao sorotipo ovis, mas não identificaram, por estas técnicas, diferenças entre as cepas.

Outra técnica, a análise de restrição de rDNA amplificado (ARDRA), que estuda o gene do fragmento $16 \mathrm{~S}$ do RNAr bacteriano, foi usada para o estudo de 50 cepas de bactérias corineformes. A técnica se mostrou útil na diferenciação entre gêneros e capaz de distinguir, na espécie C. pseudotuberculosis, os dois 
biotipos ovis e equi através da digestão com as enzimas CfoI e RsaI (VANEECHOUTTE et al., 1995)

A seqüência do fragmento $16 \mathrm{~S}$ de RNA ribossômico foi estudada por Takahashi et al. (1997) usando A.L.F. DNA Sequencer II (Pharmacia) com o objetivo de localizar filogeneticamente as cepas de C. pseudotuberculosis, que infectam caprinos e ovinos, e outras espécies do gênero Corynebacterium e gêneros relaciona-dos. De acordo com este estudo, C. pseudotuberculosis está filogeneticamente mais próximo de Corynebacterium ulcerans do que de Corynebacterium diphtheriae.

A técnica de eletroforese em gel de campo pulsado (PFGE) foi usada para caracterizar 50 cepas de C. pseudotuberculosis isoladas de caprinos, ovinos e eqüinos, no Reino Unido. Neste traba1ho, Connor et al. (2000) caracterizaram as cepas em seis "pulsotipos", conseguindo, dessa forma, evidenciar a origem de um surto de linfadenite. Esta parece ser, de fato, a técnica mais eficaz na caracterização de cepas bacterianas.

\section{Conclusões}

A identificação de C. pseudotuberculosis é passivel de ser obtida através das suas caracterísitcas morfotintoriais e de crescimento em determinados meios de cultura, graças ao seu padrão de crescimento, auxiliados por provas bioquímicas e pelo padrão de hemólise no ágar sangue. No caso de diferenciação entre cepas ou, ainda, de evidenciar cepas epidemiologicamente relacionadas, se fazem necessários métodos de biologia molecular. A caracterização genética é especialmente útil quando se pretende eleger uma cepa vacinal ou ainda quando se pretende controlar a disseminação de um determinado foco da doença em uma região.

\begin{abstract}
Corynebacterium pseudotuberculosis is the ethiological agent of the disease caseous lymphadenitis in sheeps and goats, a disease responsible for serious economic losses in the Northeast of Brazil. This review reports the characterization of Corynebacterium pseudotuberculosis by Gram strain appearance, colonial morphology, biochemical reactions and molecular methods.
\end{abstract}

\title{
Key words
}

Corynebacterium pseudotuberculosis, caseous lymphadenitis, phospholipase D

\section{Referências}

ALVES, F. S. F.; OLANDER, H. Uso de vacina toxóide no controle da linfadenite caseosa em caprinos. Veterinária Notícias, Uberlândia, n. 5, p. 69-75, 1999.

ASHFAQ, M. K.; CAMPBELL, S. G. A survey of caseous lymphadenitis and its etiology in goats in the United States. Veterinary Medicine/Small Animal Clinician, p. 1161-1165, Aug. 1979.

AYERS, J. L. Caseous lymphadenitis in goat and sheep: review of diagnosis, pathogenesis, and immunity. JAVMA, n. 171, p. 1251-1254, 1977.

BATEY, R. G. Factors affecting the yield of viable cells of Corynebacterium pseudotuberculosis in a liquid medium. Vet. Microbiol., v. 11, n. 1-2, p. 145-152, 1986a.

BATEY, R. G. Pathogenesis of caseous lymphadenitis in sheep and goats. Aust. Vet. J., n. 63, p. 269-272, 1986b.
BATTEY, Y. M.; TONGE, J. I. Human infection with Corynebacterium ovis. The Medical Journal of Australia, n. 2, p. 540-543, 28 Sept. 1968.

BENHAM, C. L.; SEAMAN, A.; WOODBINE, M. Corynebacterium pseudotuberculosis and its role in diseases of animals. Commonwealth Bureau of Animal Health, n. 32, p. 645-657, 1962.

BJÖRKROTH, J.; KORKEALA, H.; FUNKE, G. RRNA gene RFLP as an identification tool for Corynebacterium species. Int. J. Syst. Bacteriol., n. 49, p. 983-989, 1999

BRAITHWAITE, C. E. et al. Characterization of detergentsoluble proteins of Corynebacterium pseudotuberculosis. Vet. Microbiol., n. 38, p. 59-70, 1993.

BURREL, D. H. Caseous lymphadenitis in goats. Aust. Vet. J., n. 57, p. 105-110, 1981.

CAMERON, C. M.; MINNAR, J. L. Immunization of mice against Corynebacterium pseudotuberculosis infection. Onderstepoort J. Vet. Res., v. 36, n. 2, p. 207-210, 1969. 
CAMERON, C. M.; SWART, C. F. A new liquid medium for the cultivation of Corynebacterium pseudotuberculosis. J. S. Afr. Vet. Med. Ass., v. 36, n. 2, p. 185-188, 1965.

CAMERON, C. M.; MINNAR, J. L.; PURDON, M. R.; Immunizing properties of Corynebacterium pseudotuberculosis cell walls. Onderstepoort J. Vet. Res., v. 36, n. 2, p. 211-216, 1969.

CARNE, H. R. A bacteriological study of 134 strains of Corynebacterium ovis. J. Pathol. Bacteriol., n. 49, p. 313-328, 1939.

CHAPLIN, P. J. et al. Targeting improves the efficacy of a DNA vaccine against Corynebacterium pseudotuberculosis in sheep. Infect. Immun., n. 67, p. 6434-6438, 1999.

CONNOR, K. M. et al. Characterization of United Kingdom isolates of Corynebacterium pseudotuberculosis using pulsed-field gel electrophoresis. J. Clin. Microbiol., v. 38, n.7, p. 2633-2637, 2000.

COSTA, L. R. R.; SPIER, S. J.; HIRSH, D. C. Comparative molecular characterization of Corynebacterium pseudotuberculosis of different origin. Vet. Microbiol., n. 62, p. 135-143, 1998.

EGGLETON, D. G. et al. Immunization against ovine caseous lymphadenitis: comparison of Corynebacterium pseudotuberculosis vaccines with and without bacterial cells. Aust. Vet. J., n. 68, p. 317-319, 1991.

ELLIS, J. A. et al. Antigen specificity of antibody responses to Corynebacterium pseudotuberculosis in naturally infected sheep with caseous lymphadenitis. Vet. Immunol. Immunopathol., n. 28, p. 289-301, 1991a.

ELLIS, J. A. et al. Antigen specificity and activity of ovine antibodies induced by immunization with Corynebacterium pseudotuberculosis culture filtrate. Vet. Immunol. Immunopathol., n. 28, p. 303-316, 1991 b.

HARD, G. C. Comparative toxic effect of the surface lipid of Corynebacterium ovis on peritoneal macrophages. Infect. Immun., v. 12, n. 6, p. 1439-1449, 1975.

HODGSON, A. L. M.; BIRD, P.; NISBET, I. T. Cloning, nucleotide sequence and expression in Escherichia coli of the phospholipase D gene from Corynebacterium pseudotuberculosis. J. Bacteriol., v. 172, n. 3, p. 1256-1261, 1990.

IONEDA, T. Chromatographic and mass spectrometric characterization of 3-O-benzoyl methyl ester derivates of mycolic acid fractions from Corynebacterium pseudotuberculosis, C. diphtheriae and Rhodococcus rhodochrous. Chem. Phys. Lipids., n. 65, p. 93-101, 1993.

JOLLY, R. D. Some observations on surface lipids of virulent and attenuated strains of Corynebacterium ovis. J. Appl. Bact., v. 29, n. 1, p. 189-196, 1966.

LITERÁK, I. et al. Phenotype and genotype characteristics of the Slovak and Czech Corynebacterium pseudotuberculosis strains isolated from sheep and goats. Small Ruminant Research, n. 32, p. 107-111, 1998.
LOPEZ, J. F.; WONG, F. M.; QUESADA, J. Corynebacterium pseudotuberculosis first case of human infection. Am. J. Clin. Pathol., v. 46, n. 5, p. 562-567, 1966.

McNAMARA, P. J.; BRADLEY, G. A.; SONGER, J. G. Targeted mutagenesis of the phospholipase $\mathrm{D}$ gene results in decreased virulence of Corynebacterium pseudotuberculosis. Mol. Microbiol., n. 12, p. 921-930, 1994.

McNAMARA, P. J.; CUEVAS, W. A.; SONGER, J. G. Toxic phospholipases D of Corynebacterium pseudotuberculosis, C. ulcerans and Arcanobacterium haemolyticum: cloning and sequence homology. Gene, n. 156, p. 113-118, 1995.

MERCHANT, I. A.; PACKER, R. A., Bacteriología y Virología Veterinarias. 3. ed. Zaragoza: Acribia, 1975. p. 437-452.

MOURA COSTA, M. D. et al. Linfadenite caseosa dos caprinos no Estado da Bahia. Distribuição geográfica da doença. B. IBB, Salvador, v. 12, n. 1, p. 1-7, 1973.

MUCKLE, C. A.; GYLES, C. L. Characterization of strains of Corynebacterium pseudotuberculosis. Can. J. Comp. Med., n. 46 , p. 206-208, 1982

MUCKLE, C. A. et al. Analysis of the immunodominant antigens of Corynebacterium pseudotuberculosis. Vet. Microbiol., n. 30, p. 47-58, 1992.

NAIRN, M. E.; ROBERTSON, J. P. Corynebacterium pseudotuberculosis infection of sheep: role of skin lesions and dipping fluids. Aust. Vet. J., n. 50, p. 537-542, 1974.

OLIVE, D. M.; BEAN P. Principles and applications of methods for DNA-based typing of microbial organisms. J. Clin. Microbiol., v. 37, n. 6, p. 1661-1669, 1999.

PATON, M. W. et al. The spread of Corynebacterium pseudotuberculosis infection to unvaccinated and vaccinated sheep. Aust. Vet. J., n. 72, p. 266-269, 1995.

PEEL, M. M. et al. Human lymphadenitis due to Corynebacterium pseudotuberculosis: report of tem cases from Australia and review. Clin. Infect. Dis., v. 24, n. 2, p. 185 191, 1997.

QUINN, P. J. et al. Clinical veterinary microbiology. London: Wolf Publishing, 1994. p. 137-143.

RIBEIRO, O. C. et al. Avaliação de vacina contra linfadenite caseosa em caprinos mantidos em regime extensivo. Pesq. Vet. Bras., v. 8, n. 1/2, p. 27-29, 1988.

SAVELKOUL, P. H. M. et al. Amplified-fragment length polymorphism analysis: the state of art. J. Clin. Microbiol., n. 37, p. 3083-3091, 1999.

SONGER, J. G. Bacterial phospholipases and their role in virulence. Trends in microbiology, v. 5, n. 4, p. 156-160, 1997.

SONGER, J. G. et al. Biochemical and genetic characterization of Corynebacterium pseudotuberculosis. Am. J. Vet. Res., v. 49, n. 2, p. 223-226, 1988. 
SONGER, J. G. et al. Cloning and expression of the phospholipase D gene of Corynebacterium pseudotuberculosis in Escherichia coli. Infect. Immun., v. 58, n. 1, p. 131-136, 1990.

STING, R.; STENG, G.; SPENGLER, D. Serological studies on Corynebacterium pseudotuberculosis infections in goats using enzyme-linked immunosorbent assay. J. Vet. Med., n. 45, p. 209-216, 1998.

SUTHERLAND, S. S.; HART, R. A.; BULLER, N. B. Genetic differences between nitrate-negative and nitratepositive C. pseudotuberculosis strains using restriction fragment length polymorphisms. Vet. Microbiol., n. 49, p. 1-9, 1996.

SUTHERLAND, S. S.; SPEIJERS, E. J.; ANDRES, B. Comparison of the exotoxins of four strains of Conynebacterium pseudotuberculosis. Research in Veterinary Science, n. 47, p. 190-194, 1989.

TAKAHASHI T. et al. Phylogenetic positions and assignment of swine and ovine corynebacterial isolates based on the $16 \mathrm{~S}$ rDNA sequence. Microbiol. Immunol., v. 41, n. 9, p. 649-655, 1997.

TENOVER, F. C. et al. Interpreting chromossomal DNA restriction patterns produced by pulsed-field gel electrophoresis: criteria for bacterial strain typing. J. Clin. Microbiol., v. 33, n. 9, p. 2233-2239, 1995.

UNANIAN, M. M.; SILVA, A. E. D. F.; PANT, K. P. Abscesses and caseous lymphadenitis in goats in tropical semi-arid North-east Brazil. Trop. Amm. Hlth. Prod., n. 17, p. 57-62, 1985.

VANEECHOUTTE, M. et al. Evaluation of the applicability of amplified rDNA-restriction analysis (ARDRA) to identification of species of the genus Corynebacterium. Res. Microbiol., n. 146, p. 633-641, 1995.

WALKER, J. et al. Identification of a novel antigen from Corynebacterium pseudotuberculosis that protects sheep against caseous lymphadenitis. Infect. Immun., n. 62, p. 25622567, 1994.

WILSON, M. J.; BRANDON, M. R.; WALKER, J. Molecular and biochemical characterization of a protective 40-kilodalton antigen from Corynebacterium pseudotuberculosis. Infect. Immun., v. 63, n. 1, p. 206-211, 1995.

ZAKI, M. M. Relation between the toxogenicity and pyogenicity of Corynebacterium ovis in experimentally infects mice. Res. Vet. Science, n. 20, p. 197-200, 1976. 